\title{
FISCALIDAD MUDÉJAR EN EL REINO DE GRANADA: LAS RENTAS DEL QUEMPE
}

\author{
CARMEN TRILlo SAN JOSÉ
}

\begin{abstract}
SUMARIO
1. El Quempe. - 2. La documentación. - 3. Las rentas del Quempe. - 4. Fiscalidad mudéjar.
\end{abstract}

Son, en realidad, muy escasos los estudios sobre fiscalidad mudéjar en el reino de Granada. En 1959 Isabel Alvarez Cienfuegos publicó un trabajo sobre "La hacienda de los nasrîes granadinos», a través de las rentas mudéjares '. Diez años más tarde Miguel Angel Ladero Quesada daba a conocer «El duro fisco de los emires" ', en el que hacía un balance general de la recaudación tributaria en el reino nazarí y se estudiaban los derechos que pagaban los mudéjares del obispado de Málaga. También sobre la misma zona Jesús Suberviola examinó cómo tuvo lugar la implantación castellana a través del control fiscal '. En fechas más recientes Matilde Rubio Prats publicó un interesante trabajo acerca de los tributos que después de la conquista cristiana pagaban cada una de las ṭa ' $a / s$ alpujarreñas ${ }^{4}$. En este último se advierte ya la complejidad del régimen tributario nazarí, que recaía no sólo sobre las actividades económicas sino también sobre otros aspectos de la vida social. Al margen de los trabajos citados, el tema es bastante desconocido. A ello ha contribuido poderosamente la heterogeneidad del sistema fiscal mudéjar, pudiéndose constatar sensibles diferencias en la cantidad cobrada por determinados derechos en

«Miscelánea de Estudios Arabes y Hebraicos», VIII (1959), pp. 99-144.

"Cuadernos de Historia", III (1969), pp. 321-334.

- Fisco, franquicias y problemas en la repoblación de Málaga (siglos XV-XVI), "Cuadernos de Estudios Medievalesm, II-III (1974-75), pp. 149-196.

- Rentas mudéjares y estructuras de poblamiento en la Alpujarra, «III Simposio Internacional de Mudejarismow, Teruel, 1986, pp. 111-130. 
zonas muy próximas entre sí, como también otros que sólo se mencionan en algunos lugares. $A$ esto se suma, a veces, un problema añadido como es el hecho de que muchos de los nombres de los impuestos aparezcan en árabe pero se hayan conservado en fuentes cristianas escritos de oido, con las consiguientes tergiversaciones, lo que supone una auténtica dificultad a la hora de interpretas su significado. Así, por ejemplo, el caso más común es encontrarse con el término en castellano y en árabe como si fueran derechos distintos cuando se trata del mismo.

No obstante, si queremos avanzar en el conocimiento del reino de Granada es imprescindible continuar estos trabajos ampliándolos a otras zonas e incorporando un estudio de la riqueza económica sobre la que se ejercía esta fiscalidad. Como se sabe ésta se mantendría, en virtud de lo capitulado el 25 de noviembre de 1491, como había sido antes de la conquista, sin embargo sería sólo teóricamente, ya que a menudo se dieron abusos por parte de los vencedores que intentaron aplicar gravámenes a bienes que estaban por su propia naturaleza exentos de ellos, como los habices. Asimismo, no sería extraño que los mudéjares intentaran aliviar su situación fiscal declarando menos derechos que los que verdaderamente pagaban en tiempos de sus reyes. Todas estas situaciones no hacen sino complicar el panorama ya difícil de estos primeros años de contacto entre nazaríes y castellanos, pero, al mismo tiempo, son un claro ejemplo de cómo se desarrollan estas relaciones, permitiéndonos conocer qué cambios se operaron tras la conquista.

En el presente trabajo examinamos un caso concreto, la renta y los derechos que recaían sobre ella en una pequeña región del reino de Granada, el Quempe.

\section{EL QUEMPE}

El Quempe es un territorio situado al SO de Granada. Limita al N con la Vega, al E con el Valle de Lecrín y al O comunica con Alhama que es uno de los ejes fundamentales de entrada desde Málaga, pues el otro sería el constituido por Archidona-Loja. Se trata de una especie de pasillo paralelo a la Vega, de la que está separada por unas suaves lomas. En el siglo XI al-Udrî lo cita como un distrito de Ilbîra, iqlîm Qanb Qays y no es extraño, ya que realmente consituye una entidad geográfica de cierta homogeneidad. El término Quempe está compuesto de la voz latina campus, campo, y el antropónimo de la tribu árabe Qays '. Con toda seguridad los árabes Qaysíes, tal vez los que vinieron con Balýy

' M. Carmen Jiménez Mata, La Granada islámica, Granada, 1991, p. 237. 
en el 741 , se asentaron en esta zona, pues como es conocido uno de los ejércitos (jwnd/s) que llegaron con él, el de Damasco, se estableció en la cora de Ilbîra. Pero no son éstas las únicas referencias tribales que tenemos aquí, ya que otros topónimos se refieren a asentamientos árabes. Así, por ejemplo, Cacín debe su nombre al antropónimo Gassân, que parece estar en relación con los árabes Gassânies ', de la tribu Qaḥ̣ân, que eran yemeníes y, por tanto, enemigos de los anteriores a lo largo de muchos decenios después de la conquista islámica. También eran yemeníes los Hamdân, nombre que ha dado origen a Alhendín, muy próxima a este territorio y a la ciudad de Granada '. Al-Mallâhîi (ss. XII-XIII), según referencia de Ibn al-Jậab, menciona el Quempe como un iqlîm de Garnâta. En el siglo XIV este último autor en su al-Ihâțta fî Ajbâr Garnâtạ lo nombra junto con las alquerías de la Vega ${ }^{3}$. En ella puede observarse que el poblamiento del Quempe ya estaba constituido en el siglo XIV de forma parecida a como lo veremos luego de la conquista. Así, por ejemplo, Ibn al-Jaụb menciona once alquerías del total de las que componían el distrito. Por la capitulación de las «mercedes personales interesadas por Boabdil y por Abul Casim el Muleh y Yuzaf Aben Comixa, para la entrega de Granada" sabemos de cuáles se componía el Quempe, y eran las siguientes ': Escuzar '",

- L. SeCO De LuCEna PAREDES, Topónimos arabes identificados, Anejos de «Miscelánea de Estudios Arabes y Hebraicos», serie A. Granada, 1974, p. 24. Elías Teres, Linajes árabes (n ab-Andalus según la 'Ŷambara' de Ibn Hazm, «Al-Andalus", XXII (1957), pp. 55-376, espec. pp. 340-341, dice que Ibn al-Jaụ̂b lo cita como uno de los más abundantes en Granada en su época.

' E. TERES, Linajes árabes, A.A., p. 344, dice que el manzil de Hamdân está a seis millas de Granada y se trata, por supuesto de Allhendín. Añade además que el linaje se conservó hasta los últimos tiempos del reino nazarí. L. SECO DE LUCENA PAREDES, Topónimos árabes identificados, p. 13. IBN AL JATB, Al-Ihạta, p. 128, menciona qarya Riqâq wa Hamdân, de la que dice que era el extraordinario Ibn Yazîd al-Šimr Ŷaddu Ibn Adhà. Pierre GuICHARD, Al-Andalus. Estructura antropológica de una sociedad islámica en Occidente, p. 309.

- IBN AL-JAṬiB, Al-Ihâța fí ajbâr Garnâta, Ed. Mohammed Enan, El Cairo, 1973, p. 128.

- Miguel GARrido AtienZA, Las capitulaciones para la entrega de Granada, Granada, 1910, p. 245: «Otrosy, que todo el quempe que se llama çabi casy, todo lo poblado y despoblado, alto y vaxo, y todas las minas de sal ó de otras cosas que sean en las dichas salinas, que es las salinas y la sal dellas, y sus alcarías de escusar, y agrón, y bayara, y ynçar, y topolar, y caucín y su Rio, y huelma, y tijarjal, y alcaría dy boyar, y el alcaría de bodoul, y bonares, y el alcaria sunllana, y alcaría de sanbriça é jarjilis y almachar, esto todo es del dicho quempe, sea dado y firmado de sus altezas en juro de heredad, que lo podamos vender é empeñar y fazer é desfazer, y que lo hereden nuestros nietos é visnietos, en todo lo poblado y despoblado, y pastos, y dehesas, y todos sus diesmos y pechos y derechos; y que todos los que hizieren yr allí a poblar de los moros, que non gelo defienda ningunon.

${ }^{10}$ L. SECO DE LUCENA PAREDES, Topónimos árabes identificados, p. 40, qaryat Askêdar, es versión árabe de otro anterior. 
Agrón ", Baira "', Ynçar ", Topolar, Cacín "4 y su río, Huelma, Tijarjal ", Boyar, Bodoul, Bonares, Sunllana, Sanbriça, Jarjilis, Almachar. En el asiento definitivo que se firma con el Muleh y Aben Comixa se les hace merced, entre otras cosas, de la totalidad del Quempe, pero sin explicitar el número de alquerías que lo componían. Las últimas referencias de época medieval corresponden a un documento de 1503 en el que se nombran las siguientes ": La Malaha ${ }^{1}$, Escuçar, Pera ${ }^{18}$, Focullar, Guelima ${ }^{14}$, Agron, Vchichar ${ }^{20}$, Tajarjal, Duyar ", Muneyras y Alcola. Son menos que las que se citan en la capitulación pero puede deberse, primero, a que en ésta se incluían también los despoblados y, en segundo lugar, a que después de la rebelión de 1500 es lógico que la población de muchas de ellas hubiera desaparecido. Así, un testigo, Fernando Enrríquez el Pequeñí, que fue cadí mayor de Granada y la Alpujarra, a la pregunta de cuánto rentaba el Quempe en el tiempo de la conversión general de los mudéjares responde que las tierras del Quempe estaban algo despoblades e agora estan mas pobladas pero que no sabe lo que entonçes rentauan ni lo que agora pueden rentar ${ }^{22}$. Actualmente sólo quedan siete núcleos poblados:

"L. SeCo De Lucena Paredes, Topónimos árabes identificados, p.6, dice que es Agrûm, versión árabe de otro anterior, aunque en IBN AL-JAṬIB, Al-Ihâata., ed. Enan, p. 134, lo encontramos como Al-Garûm.

:. IBN AL-JATIB, Al-Ihâtạ, p. 129, qarya Bayra.

" IBN AL-JATiB, Al-Ihâtạ, p. 128, qarya Inqar. L. SECO DE LUCENA PAREDES, Topónimos árabes identificados, p. 50, dice que es versión árabe de otro anterior. Por su parte, Miquel Barceló, Notes berbers $i$ sabarianes entorn del Sharq al-Andalus, en Sobre Mayûrqa, "Quaderns de la Ca La Gran Cristiana», II (1984), pp. 133-141, espec. pp. 135 y 136, lo relaciona con el ŷuz Inkân de Mallorca y cree que se trata de un topónimo de origen beréber que significaría elevación montañosa.

I4 IBN AL-JAṬIB, Al-lhâtạ, p. 128, qarya Gassân.

1s IBN AL-JAṬiB, $A$-Ibầta, p. 128, la nombra como qarya Tayaryar. L. SECO DE LUCENA PAREDES, Topónimos árabes identificados, p. 73, dice que es versión árabe de otro anterior.

${ }^{16}$ A(rchivo) G(eneral) de S(imancas), Cámara-Pueblos, leg. 8, fol. 276. Hoy es Acula. IBN AL-JATiB, Al-Ihâța, p. 128, la menciona como Aqula.

'IBN AL-JiTib, Al-Ihâta, p. 129, qaryat al-Mallâhạ, de la que era Muhammad Ibn 'Abd al-Wâhid al-Gâfiquî Ảbû l-Qâsim al-Mallâhî.

1s Debe ser identificada con Beira, según dice L. SECO DE LUCENA PAREDES, Topónimos árabes identificados, p. 20.

19 L. SECO DE LUCENA PAREDES, Topónimos árabes identificados, p. 48, hoy es Ventas de Huelma, qaryat al-Wâlima, alquería de la Anfitriona. L. SECO DE LUCENA PAREDES dice también que cInan en la edición de la Ihâta , El Cairo, 1973, tomo I, p. 128, la menciona incorrectamente como qarya Wâla.

20 L. SECO DE LUCENA PAREDES, Topónimos árabes identificados, p. 65, es versión árabe de otro anterior.

21 IBN AL-JAṬ̂B, Al-Iḥ̂tâ, p. 129, nombra una qarya Dûŷar.

22 AGS, Cámara-Pueblos, leg. 8, fol. 276. 
La Malá, Escuzar, Castillo de Tajarjal, Agrón, Acula, Cacín y La Pera, aunque han quedado huellas en la toponimia menor de algunas de las antiguas poblaciones. Sólo una prospección arqueológica superficial por la zona podría arrojar luz al respecto y ayudar a configurar el poblamiento del Quempe.

\section{LA DOCUMENTACIÓN}

El documento que va a permitirnos aproximarnos a la fiscalidad mudéjar en esta región se halla en el Archivo General de Simancas, Cámara-Pueblos, leg.8, fol. 276. Consta de seis folios recto y vuelto sin numerar. Es conocido hace tiempo, pero sólo se ha utilizado parcialmente ${ }^{27}$. Está dividido en cuatro partes. Una primera, que es una cédula de la reina Isabel, con fecha 3-XI1503, dirigida a Alonso Enríquez, corregidor de Granada, por la que ordena que se averigüen las rentas y bienes que Abulcaçin el Muleh tenía en el Quempe antes y después de que revertieran a la Corona por compra y cuando fueron dadas en merced al monasterio de la Concepción de Granada. Una segunda, en la que se incluye un breve interrogatorio a diversos testigos, mudéjares en su mayoría, sobre las mercedes citadas. Una tercera, que es una relación de las rentas del Quempe desde el año de 1500 al 1504 y, finalmente, una carta de Alonso Enriquez a la reina dando respuesta a la información que pide en su cédula.

Existe, sin embargo, una Relación de los derechos moriscos del Quempe, actualmente ilocalizable, de la que se sirvió Eguilaz para componer su Glosario etimológico de palabras españolas de origen oriental ${ }^{24}$.

El contexto histórico de nuestro documento son los años inmediatamente posteriores al sofoco de la rebelión mudéjar, la cual supuso la conversión de los musulmanes al cristianismo de forma casi inmediata. Estos momentos son de cierta confusión para el poder castellano que está instalándose ya de manera definitiva en los resquicios que ahora deja libres la oligarquía islámica. No es extraño, por tanto que ello fuera acompañado de una reorganización a todos los niveles, especialmente fiscal. De hecho, tras la capitulación de junio de 1500 con los nuevamente convertidos, éstos serán incorporados al sistema tributario

"Rafael Gerardo Peinado Santaella y José Enrique lópez de Coca Castañer Historia de Granada. La época medieval. Siglos VIll-XV. Granada, 1987, pp. 339-342.

${ }^{24}$ Leopoldo EgUILAZ Y YANGUAS, Glosario etimológico de las palabas españolas (castellanas, catalanas, gallegas, mallorquinas, portuguesas, valencianas y bascongadas) de origen oriental (árabe, bebreo, malayo, persa y turco). Granada, 1886 (reimp. Madrid, 1974). 
al que estaban sometidos los cristianos viejos. Este momento tan crucial supuso también la concesión de mercedes a la oligarquía mudéjar con objeto de fomentar nuevas conversiones.

En 1495 el monasterio de la Concepción de San Jerónimo de Granada recibe en merced las rentas que habían tenido Bulcaçin el Muleh hasta que marchó allende. Se le hacía entrega de un total de 203.500 maravedís anuales situados en las siguientes rentas: las tiendas que habían sido propiedad de las reinas moras, rentas diversas de la ciudad de Granada que no se especifican, las ya mencionadas del Quempe y los pastos de Sierra Nevada ${ }^{2}$. Tampoco puede verse como aislado este hecho, ya que en estas fechas la Iglesia recibe donaciones de las nuevas propiedades que caen en manos de la Corona. Sin ir más lejos buena parte de los habices de la ciudad de Granada y su Tierra revertirán en ella. En estos años se convierte en un elemento fundamental de control de la población vencida.

La documentación sobre el monasterio de San Jerónimo es abundantísima. Baste recordar que es uno de los más importantes de Granada y que ya desde antes de la conquista le habían sido concedidos privilegios sobre determinadas tierras próximas al reino nazarí. Estos se verán acrecentados desde la época de los Reyes Católicos en adelante. Disponían de bienes en toda Andalucía y, muy especialmente, en Granada. Pero el estudio de esta documentación es objeto de una reciente investigación por nuestra parte y aunque, dado el carácter de la misma, pensamos que dará a conocer muchos aspectos del reino de Granada, aun es pronto para adelantar resultados.

\section{LAS RENTAS DEL QUEMPE}

Las rentas del Quempe se dieron en merced a Bulcaçin el Muleh y a Yuçaf Aben Comixa como respuesta a su colaboración en la entrega de Granada. Fueron objeto de una capitulación especial que se firmó el 25 de noviembre de 1491 y se amplió el 30 de diciembre de $1492^{26}$. Por la primera se les hacía entrega por juro de beredat para syempre jamas de los lugares del Valle de Lecrín, con Lanjarón, del Quempe y de las salinas de la Malaha, llevando cada uno de ellos la mitad, de la manera siguiente:

las villas et lugares de las taas de Alecrín et Lanjaron, et de sus fuersas et fortalesas, que agora tiene et posee el dicho Rey Baaudeli, et de todo el término que vá desde la

2s A(rchivo) de la $\mathrm{R}$ (eal) $\mathrm{Ch}$ (ancillería) de $\mathrm{G}$ (ranada), cab. 513, leg. 2566, pieza 38. Vease el apéndice documental.

${ }^{26}$ Miguel GARRIDO ATIENZA, Las capitulaciones, pp. 295-302. 
Malahá á Cacín, a la mano izquierda fasta partir con Cherubien; et ansimismo del aldea et salinas de la Malahá, é de todos los pechos et derechos et otras rentas, et diesmos, et herencias y poblado et despoblado, et otras cosas á nos pertenecientes en las dichas Villas et Logares, et Salinas et término, para cada uno de vosotros la mitad de todo ello para que sea vuestro, et de los dichos vuestros subşesores, por juro de heredad para siempre jamás, et para que podades gozar et gocedes cada uno de vosotros de la dicha mitad de las dichas rentas, et diesmos, et pechos, et derechos, et rentas, et herencias de todo lo susodicho; et de la justiçia de las dichas Villas et Logares de las dichas taas de Alecrin et Lanjaron, como Señores de todo ello, como buenos vasallos et súbditos nuestros, agora et en todo tiempo para siempre jamás, sin que ninguno vos pueda quitar de todo ello, salvo que sea propio vuestro, et que lo podades rodo vender et empeñar, é faser é desfaser de todo ello lo que quisiéredes; con tanto que quando lo quisiéredes vender ó enagenar en qualquier manera, seamos primeramente requeridos si lo quisiéramos comprar para nos, et si comprarlo quisiéremos vos mandaremos dar por ello lo que entre nosotros y vosotros fuere convenido, et si nosotros non quisiéremos comprar, vos lo dexemos vender á quien quisierdes é por bien tovierdes; et ansi mismo vos fasemos merced de la otra parte de la tierra del quinpen ${ }^{27}$

En la misma capitulación se daban en merced una serie de propiedades para los hijos de ambos, Abrahen y Mahomad Aben Comixa, por un lado, y Mahomad y Hamet el Muleh, por otro. Para los primeros eran la alquería de Puliana con su anejo Jun y la hacienda que dejó en Granada y la Alpujarra Abulhuceyd Aben Male. Mientras que los segundos se hacían cargo de la alquería de Otura, en la Vega, y de varias propiedades que Mahomad Ben Alhage tenía en el Valle de Lecrín, la Alpujarra y Granada ${ }^{28}$. Una cédula real posterior ampliaba la merced a los alcaides Bulcaçin el Muleh y Yuçaf Aben Comixa incluyendo el campo de Dalías y las salinas en él situadas, así como la cesión a un hijo de este último del tercio de las rentas de la ṭấa alpujarreña de Los Céjeles ${ }^{x}$.

Como vemos, después de la conquista de Granada, los Reyes enajenan parte del reino entregando a Boabdil la Alpujarra ${ }^{\text {" }}$ y a sus colaboradores los territorios inmediatamente al SO de la ciudad. Se queda, sin embargo, la Corona con el control del resto del territorio y de la Costa.

Las salinas de La Malá habían sido entregadas antes como resultado de las capitulaciones que en 1489 se firmaron con El Zagal y con Yahia Alnayar, alcaide de Baza, por las cuales se rindió la parte oriental del reino. Al primero le dieron el 10 de diciembre de 1489 las tâáa/s de Andarax, Valle de Lecrín y

"Idem, Las capitulaciones, pp. 296 y 297.

a Idem, Las capitulaciones, Pp. 297 y 298.

- Idem, Las capitulaciones, p. 299.

* Idem, Las capitulaciones, «capitulaciones entre los Reyes Católicos y Boabdil, acerca de los intereses particulares de éste y de su familiaw, p. 261. 
Lanjarón, con sus rentas, pechos y derechos, la mitad de las salinas citadas y otra tanta renta equivalente a la otra mitad. La parte de las salinas que faltaba las renunció en Bulcacin Venegas, alguacil de Granada, y en su cuñado Yahia Alnayar ".

Cuando en octubre de 1493 se marcha Boabdil con sus principales adeptos son los Reyes los primeros en comprar sus propiedades. Estas se evaluaron en distintos precios hasta que se produjo la adquisición definitiva. Así los citados alcaides pedían 4.500 castellanos cada uno "repartidos de la siguiente forma ":

- la tầa de Dalías y de las salinas: 9.250 ps.

- el Valle de Lecrín: 15.000 ps.

- la Malaha y las salinas: 12.500 ps.

- la renta del Quempe: sin especificar.

Pero en el último acuerdo, correspondiente al 18 de septiembre de 1493 se entregan 2.000 castellanos de oro a Aben Comixa y 3.250 a Bulcaçin el Muleh ", teniendo en cuenta que este último disponía de algunos bienes más ". Después de esto las rentas del Quempe se cederían al monasterio de la Concepción de San Jerónimo de Granada. Algunos testigos declaran que no percibió durante algunos años las rentas de las salinas de La Malá ${ }^{16}$, sin embargo por la carta de merced conocemos que en 1495 tenía situadas allí 200 fanegas de sal ".

A excepción de ésta, que era la riqueza fundamental de la teâa de Dalías y del Quempe, el resto de la economía se basaba en la actividad agrícola y en la ganadería. Estamos en una zona en la que, seguramente por la composición del suelo, el secano es muy extenso. Esto no quiere decir que fuera la parte más

"Miguel Angel LADero QueSADA, Granada después de la conquista. Repobladores y mudéjares, Granada, 1988, pp. 339-344.

12 Colección de Documentos Inéditos para la Historia de España (en lo sucesivo Co.Do.In), VIII, p. 446.

"Las cantidades están reducidas a la mitad.

is Co.Do.ln, XI, p. 544.

" "Y porquel dicho Bulcacin el Muleh tiene demás de lo quel dicho Aben Cominja tiene, el tercio de Zuchal, y tres mill reales situados en las rentas de la zapatería desta cibdad; é las rentas de Autura, que esto con todo lo otro vende, cede é traspasa en sus Altezas el dicho Bulcacin el Muleh, seyéndole pagado por ello al respeto...n, Co.Do.In, VIII, p. 453.

16 Así, por ejemplo, Mahomad Alazeraque, vecino de La Malá, asegura que «vydo a los dichos frayles cobrar e reçebyr los derechos de todo ello saluo de las salinas que no cobraron çiertos años», AGS, Cámara-Pueblos, leg. 8, fol. 276.

"ARCHG, cab. 513, leg. 2566, pieza 38. 
importante cualitativamente hablando, ya que eran los cultivos de regadío los principales, como ocurría en casi todo el reino de Granada. En otros lugares el secano prácticamente no existe, especialmente en los territorios de montaña. Así, por ejemplo, en la Alpujarra o el Valle del río Verde, territorio éste último de Almuñécar, suele ocurrir que por encima de la tierra irrigada sólo está el monte. Entre ambos se halla la alquería, en la parte superior, por tanto, del área irrigada y con objeto de no interferir ésta. Probablemente, en épocas de hambre se rozaba el monte y se cultivaba de cereal, especialmente de aquel que soportoba mayores altitudes y condiciones más adversas. También era frecuente rozarlo para pastos, llegándose a formar un bosque adehesado o aclarado.

Podemos decir, entonces, que hay lugares del reino nazarí en donde el secano apenas se conoce. Sin embargo, el Quempe debía ser distinto, ya que la existencia de suelos salinos, así como, incluso, de un río salado (Mâliḥ) nos hablan de suelos secos y frágiles. En el caso de La Malá sabemos que había una fuente de agua caliente que, seguramente, era explotada desde la época prehistórica, protohistórica y antigua ${ }^{18}$, lo mismo que las salinas. Este agua era utilizada para regar. El propio Libro de Apeo confirma, además, que ésta era un bien escaso: que ai vna fuente manantial en el dicho lugar de la Malaba de agua caliente que sirbe de baño que sera una hazada de agua poco mas o menos $e$ toda el agua que de ella sale la recoxen en vna alberca que estan echas " $y$ despues de llena ban regando por su orden haza por haza sin poder saltar a otra asta que se acaba lo que es de riego ${ }^{\text {*0 }}$. Y continúa diciendo que ansimismo ay otras fontezuelas enpero son saladas ${ }^{41}$. El texto revela que el agua no era abundante en esta alquería, pues se regaba siguiendo un riguroso turno. Ahora bien, no se puede ir más allá ni señalar que aquí se daría el sistema que Th. Glick define como yemení en el que el agua no está adscrita a la tierra y, por lo tanto, cuando un regante no la necesita la puede vender, que es característico de zonas, como el Yemen, en donde el agua escasea como los oasis del Sahara o el S de Arabia, mientras que en España se da en lugares cuyo riego depende de fuentes ${ }^{42}$. En este sistema el agua no pertenece a la tierra y puede venderse o enajenarse a parte. En el reino de Granada se daban casos de venta de turnos de agua, pese a

18 Eduardo FRESNEDA PADILLA y M.O. RODRÍGUEZ ARIZA, El yacimiento arqueológico de los Baños (La Malá, Granada), "Cuadernos de Prehistoria de la Universidad de Granada», VII (1982), pp. 331-357.

is Sic.

" ARCHG, cab. 5, estante a.3, leg. 106, fol. 23v.

"ARCHG, cab. 5, estante a.3, leg. 106.

12 Thomas GLICK, Regadio y técnicas bidraúlicas en al-Andalus: su difusión según un eje Este-Oeste, "Actas del Ier Seminario Internacional. La Caña de Azúcar en tiempos de los grandes descubrimientos (1450-1550)». Motril, 1990, pp. 83-98, p. 92. 
que a este respecto varios fuqâha, se pronunciaban en contra " $e$, incluso, de la institución de algunos como habiz ". En ciertos contratos de compra-venta de época nazarí, referidos a propiedades situadas en el Quempe, concretamente a la alquería de Guelima (hoy Ventas de Huelma), se especifica que se venden con el riego que tienen lo que dellas se riega, e es de uso e costunbre para ello. También en la escritura de partición de los bienes del alguacil Mahamad Aben Çalema entre su mujer y sus cuatro hijos, se le da a uno de ellos la tierra y el agua del siguiente modo: la parte que pertenese al difunto del agua del Cavril es de las pertenensias de las heredades que cupieron Abulcafin en el alcaria de Juriliana, que si fuere desapoderado Abulcaşin del agua del Cavril que no pueda pedir por razon dello a los otros berederos cosa alguna".

Junto a esta área irrigada el secano tenía un papel relevante. El análisis de los documentos arábigo-romanceados, cuyas fechas oscilan entre 1348 y 1454, que se refieren en su mayoría al Quempe, así lo refleja *. Aunque no podemos establecer cual sería la relación exacta entre el regadio y el secano si hay que señalar que está presente en todos los documentos citados.

En cuanto a la propiedad de la tierra estamos en unos momentos en que ha empezado a producirse una disgregación del medio tribal, que se puede constatar, en general, en todo el reino de Granada. A ello han contribuido particularmente las herencias, dotes y la compraventa, así como la práctica habitual de la exogamia ${ }^{4}$. Con frecuencia el nombre del individuo, que recoge ya la documentación castellana, no habla del clan o tribu a la que pertenecía sino del lugar de donde procede. De los antiguos Qaysíes que al principio de la conquista estaban asentados en estas tierras, sólo quedan algunos descendientes que residen en la ciudad de Granada ${ }^{*}$. Parece que existe una oligarquía rural que detenta gran parte de las propiedades y que está emparentada entre sí. De este modo, en el Quempe, durante la segunda mitad del siglo XIV la hija del alguacil Mahamad, hijo de Abdalla Aben Ragi el Haximi, el Tahanichili, llamada Cazmora era la esposa del alcaide Yuzaf, hijo de Hamet Aben Hayre el

" José LÓPEZ ORTIZ, Fatwas granadinas de los siglos XIV y XV, "Al-Andalus», VI (1941), pp. 73-127, espec. p. 105.

44 AGS, CMC, 1 época, leg. 131.

43 M. José Osorio PÉrez y E. de SANTIAGo Simón, Documentos arábigo-granadinos romanceados, Granada, 1986, documento 4.2, con fecha 31 de enero de 1401, p. 70.

* M.J. Osorio Pérez y E. de SANTIAGo Simón, Documentos arábigo-granadinos romanceados, passim.

47 Antonio Malpica Cuello, de la Granada nazari al reino de Granada, en De al-Andalus a la sociedad feudal: los repartimientos bajomedievales, Barcelona, 1990, pp. 119 153, espec. pp. 132 y 133.

to Luis SECO DE LUCENA PAREDES, Documentos arábigo-granadinos, Granada, 1974. 
Abdari ". También Marién, la hija del antiguo alcaide Mahamad el Geziri, era viuda del alcaide Mahamad Aben Çalema Alançari, que detenta además el título de alguacil ". Asimismo parece que existe una cierta continuidad en los cargos. El alguacil Abdalla, hijo del viejo alguacil Abrahen Aben Abdulçamad Alazdi El Moxiqueri, vendió ciertas propiedades a su hijo el también alguacil Ali, ciertas propiedades en Guelima, en el Quempe".

Las actividades pecuarias debían ser importantes en la zona, sobre todo, en relación con la existencia de salinas. Sabemos que la sal constituía un elemento fundamental en la alimentación del ganado, ya que además de contribuir a su engorde facilita la digestión del nutriente ingerido ". La ganadería del reino nazarí era transhumante y, en los casos que conocemos, estaba supeditada a la agricultura. Podría decirse, incluso, que existía al margen de ésta, ya que la infraestructura de regadío dominante en buena parte del territorio granadino, así como el carácter de pequeñas parcelas de policultivo en las que continuamente se está produciendo, no permitirían la entrada del ganado en ellas a no ser provocando grandes daños. Por ello la transhumancia era fundamental, ya que permitía al ganado alimentarse en todas las épocas del año, a lo que contribuía el hecho de que, al menos teóricamente, todos los pastos eran comunes. Ya veremos, que existían algunas restricciones a este principio general. El ganado de la Vega y de Sierra Nevada se trasladaba en el invierno a los campos de Motril, Zafarraya y, sobre todo, Dalías, en donde además podía hacer acopio de sal. Durante el verano subían a las cumbres de Sierra Nevada. Probablemente, los de la Vega entraban a su paso hacia los pastos mencionados o a los de Sierra Almijara, en La Malá, en donde podían tomar sal convenientemente.

Era la sal la mayor riqueza de la zona, de ello ya se habían dado cuenta los romanos " y, probablemente, otros pueblos más antiguos las habían explotado, pues muy próxima a ella se encuentra un yacimiento prehistórico ${ }^{54}$. De su

9.

9 M. J. OSORIO PÉREZ y E. de SANTIAGo Simón, Documentos arábigo-romanceados, p.

*Idem, Documentos arábigo-granadinos, p. 63.

"Idem, Documentos arábigo-romancedados, doc. 10.

"IBN AL-AWWAM, Kitab al-filaha. Traducido al castellano y anotado por Josef Antonio BANQueri. Ed. J.E. HeRnández Bermejo y E. Garcí SÁnCHEZ, Ministerio de Agricultura, Pesca y Alimentación, 1988, II, p. 531. Gabriel ALONSO DE HeRrerA, Obra de Agricultura. Ed. José Urbano Martínez Carreras, Biblioteca de Autores Españoles, CCXXXV, Madrid, 1970, p. 291.

"Antonio Malpica Cuello, Fiscalidad y comercio de la sal en el reino de Granada en la Edad Media, «Das Salz in der Rechtsund Handelsgeschichte. Internationale Salzgeschichtegung», Hall in Tirol, 1991, pp. 65-94, espec. p. 83.

" E. FRESNEDA PADIlla y M. Oliva RODRíGUeZ ARIZA, El yacimiento arqueológico de Los Baños, "Cuadernos de Prehistoria de la Universidad de Granada", VII, (1982), pp. 331 357. 
importancia en época nazarí no nos cabe ninguna duda aunque, según parece, se vio acrecentada con el establecimiento del monopolio salinero en época ya de los Reyes Católicos. Así, sabemos, por ejemplo, que a pesar de tener la concesión de las salinas El Muleh y Aben Comixa, no podían vender la sal en Granada, por lo cual hubieron de ofrecer la mitad de ellas a los Reyes a cambio de obtener las "cédulas guía» que les permitieran llevarla a la ciudad y a otros lugares del reino ". Al mismo tiempo se prohibía la entrada de sal foránea en los términos en donde había de venderse la de La Malá y la de Dalías, que eran los siguientes: Granada y su Tierra, la Alpujarra y la franja costera entre Albuñol y Maro, aunque no siempre se consiguiera tal propósito ". El 28 de mayo de 1493 volvieron a arrendarse las salinas de La Malá a cuatro mudéjares por el periodo de un año ". A partir de 1499 se arrendaron por seis años con el resto de las salinas del reino.

Resulta casi imposible conocer por las opiniones de los testigos interrogados lo que rentaban los derechos de las alquerías del Quempe en los primeros momentos de su concesión. Sin embargo, existe una relación más precisa correspondiente a los años inmeditamente posteriores a 1500. Así, Alonso de Sançola, clerigo de la orden de Burgos, ante la petición de la reina de conocer cúal era la renta de esta tierra refiere lo siguiente ${ }^{\text {s: }}$ :

\section{AÑO CONCEPTO RENTA EN ESPECIE EN METALICO}

\begin{tabular}{lll}
1500 & diezmo del pan & \multicolumn{1}{c}{$\begin{array}{l}1.577 \text { fanegas y } 6 \text { cls. } \\
\text { de pan terciado }\end{array}$} \\
& diezmo de corderos, queso & $7.800 \mathrm{mrs}$. \\
& y lana & \\
diezmo del resto & $2.000 \mathrm{mrs}$. \\
$1501 \quad$ todos los diezmos & $87.000 \mathrm{mrs}$.
\end{tabular}

"AGS, Guerra Antigua, leg. 1314, fol. 34, en Miguel Gual Camarena y José Enrique LÓPEZ DE COCA CASTAÑER, La sal del reino de Granada. Documentos para su estudio, "Cuadernos de Estudios Medievalesw, II-III (1974-75), pp. 259-296, espec. pp. 269270.

"M. Gual Camarena y J.E. López de Coca Castañer, la sal en el reino de Granada, p. 261.

"AGS, Guerra Antigua, leg. 1314, fol. 44, en M. Gual Camarena y J.E. López de

Coca Castañer, La sal del reino de Granada, pp. 270-272.

" AGS, Cámara-Pueblos, leg. 8, fol. 276.

"Celemines.

6n) Es decir, dos partes de trigo y una de cebada. 
ANO CONCEPTO RENTA EN ESPECIE EN METALICO

1502 todos los diezmos

1503 todos los diezmos

TOTAL

2.027 fanegas y 6

$361.206,5 \mathrm{mrs}$.

celemines pan

\section{FISCALIDAD MUDÉJAR}

La fiscalidad nazarí era muy compleja y heterogénea, como tendremos ocasión de ver. Una misma actividad económica, como por ejemplo, la ganadería estaba sometida a un gran número de impuestos, que se aplicaban por distintos conceptos y tenían valores diferentes según la región en donde se imputaran. Sólo en la zona malagueña existían hasta seis regiones fiscales ". Además se gravaban no sólo la economía sino, casi puede decirse, cualquier actividad social. De este modo, por ejemplo, es conocido que existían en Granada dos impuestos para las zambras o fiestas que eran el tarcón y el cequi ${ }^{\circ:}$. En la tâa $a$ de Marchena encontramos que existe un derecho de la que conģierta las novias y otro llamado de los gayteros ${ }^{63}$. Prácticamente ningún aspecto de la vida nazarí escapaba al control del Estado. Solamente parece haber una excepción, los bienes habices, es decir, bienes cuya renta se dedicaba a fines piadosos y públicos. Sin embargo, nos caben algunas dudas al respecto, ya que las informaciones que tenemos en este sentido son posteriores a la conquista castellana, y podrían haber existido ciertas tergiversaciones por parte de los mudéjares. En enero de 1430, la cancillería de Muhammad IX el Zurdo, expedía un decreto de exección de impuestos para los bienes habices de la mezquita de Berja ${ }^{64}$. Tal vez, habría que entender, por ello, que el resto de los habices sí estaban sometidos al fisco. Pero, de momento, es difícil saberlo.

Por el asiento de 1491 se mantenía el régimen tributario nazarí. No

"José Ramón Ramos IsAbeta, Política ganadera de los Reyes Católicos en el Obispado de Málaga, Málaga, 1988, pp. 17 y ss.

62 M.A. LADERo QUeSADA, El duro fisco, p. 326.

" EMR, leg. 50.

" Luis SeCo De LuCena PARedes, Mubammad IX, sultán de Granada, Granada, 1978, p. 55. 
obstante, llevar a la práctica este capítulo no fue fácil. Así, los musulmanes de la Alpujarra se negaron a pagar algunos tributos por considerar que eran nuevos, tales como el tabinil y el alacer de los olivos "que no llegaron a cobrarse. También protestaron por otros como el fardatalbani, fardatamoman y cadaben e lieva del pan a la şibdad de Granada, pero con menor éxito ${ }^{* 6}$. Por otra parte, los castellanos intentaron gravar con impuestos los habices, lo que suscitó polémica entre los mudéjares, siendo finalmente exentos de pago estos bienes".

El documento sobre el que apoyamos este estudio de fiscalidad mudéjar en el Quempe ${ }^{\text {so }}$ sólo va a permitirnos analizar algunos derechos porque, en realidad, no es una relación de éstos sino un interrogatorio hecho a testigos mudéjares. Algunos de ellos no parecen recordar el nombre de los impuestos ni a qué se aplicaban exactamente por lo que obtenemos un conocimiento parcial del régimen tributario en esta zona y nos obliga a compararlo con lo que sabemos de otras regiones del reino de Granada. De hecho, los testigos sólo hacen referencia a tres impuestos: el diezmo, los derechos del ganado y la almaguana, que son una mínima parte del conjunto de tributos a los que se veían sometidos los habitantes del reino nazarí. Sin embargo, por la Relación de derechos moriscos del Quempe que menciona Eguilaz en su Glosario podremos hacer referencia a otros más. No obstante, está claro que no disponemos de una relación completa y, por tanto, habría muchos más impuestos, con seguridad similares a otras zonas, que desconocemos.

El único impuesto legal de acuerdo con el Corán era la zakâ. Esta voz designaba la limosna que, al principio, de una forma más o menos arbitraria los musulmanes debían pagar a la comunidad por prescripción del Profeta y que estaba destinada a las siguientes grupos sociales sociales: a los pobres e indigentes, a los esclavos, los viajeros, y, en general, a la causa de Allâh. Más tarde, la sistematizó Abû Bakr, dándole un sentido claramente fiscal y fijando su valor ". Se aplicaba sobre los productos agrícolas cultivados para la alimentación, sobre los frutos (especialmente, dátiles y uvas se nombran en la tradición), el ganado, oro y plata, y, finalmente, las mercancías. En concreto, las dos primeras categorías pagaban el $10 \%$ y, en caso de que estos productos agrícolas fueran el resultado de la irrigación artificial, el $5 \%{ }^{\circ}$. Para la tercera,

6) AGS, Libro de Cédulas, 4, fols. 158 v.-159 r.

« AGS, Expte. de Ha., leg. 4.

${ }^{6}$ Co.Do.In., tomo XI, p. 522. AGS, Epxte. Ha., leg. 4.

${ }^{68}$ AGS, Cámara-Pueblos, leg. 8, fol. 276.

"I) Joseph SCHACHT, Zakât, en Encyclopédie de l'Islam, ed. W. ARNOLD y otros, Leyden, 1914-1938, tomo VI, pp. 1270-1273.

"J. SCHACHT, Zakât, p. 1272. Felix M. PAREJA, Islamologia, Madrid, 1952-1954, tomo II, p. 537. 
se aplican reglas complicadas que tenían en cuenta la especie animal y el número. En cuanto a las fortunas, incluyendo los metales preciosos almacenados, y las mercancías también eran objeto de la zakâ, cuyo valor consistía, entonces, en el 2,5\%". A nosotros ha llegado, a través de la documentación castellana, el término cequi como un impuesto que recae sobre el ganado y el paso de las mercancias ". Aunque, en el caso primero, su valor depende mucho de las variantes señaladas, parece que, cuando se refiere al ganado menor grava, como veremos, 1 cabeza por cada cuarenta en un hato de menos de 100 reses, lo que supone el 2,5\% ". Por su parte el capital acumulado pagaba, en el reino de Granada, el cequi, cuyo valor era del $10 \%$, como veremos, y no del $2,5 \%$ como aconsejaba la tradición. En cuanto a las mercancías, éstas estaban sujetas al pago, por un lado, del magraner, que es el $10 \%$ de todo lo que se vende y se compra, a excepción de los inmuebles, y, por otro, del derecho de tránsito, que consistía en el 2,5\%, excepto si habían sido compradas en la alcaicería de Granada, en cuyo caso debían dar el 1,5\%. En la Alpujarra se menciona también un derecho del cequi de los mercaderes que es de cada $C L$ pesantes con que tratan XXXVII dineros e medio e sy con mas trata al respeto ", es decir, el 2,5\%. Es necesario señalar que algunos otros impuestos que conocemos en época nazarí, como la almaguana y el alacer, entre otros, gravan también con el 2,5\% los bienes inmuebles y los frutos de los árboles y viñas, respectivamente. Es decir, buena parte de los derechos mudéjares obedecen a alguna de estas dos cantidades, ello ó el 2'5\%. Parece, incluso, que conforme se van creando nuevos impuestos, hay una tendencia a que coincidan con alguno de los porcentajes mencionados. Sin embargo, esta comprobación no es posible hacerla para la totalidad de los derechos mudéjares, ya que, como hemos mencionado, las relaciones de rentas suelen ser muy escuetas, o bien sólo se refieren a una zona concreta y es difícil generalizar.

Es un lugar común decir que, a excepción del diezmo, casi todos los impuestos eran ilegales. En realidad, y según hemos visto, el diezmo era una de las expresiones del único derecho legal, la zakâ. De hecho, una parte de los impuestos que analizaremos también procedían de ella. Así, podemos decir que los nuevos impuestos que va generando el Estado islámico remiten en su cuantía casi siempre a la tradición coránica. Conforme se apretaba el cerco castellano contra el reino nazarí y éste se veía obligado a pagar parias cada vez más elevadas se fueron creando nuevos impuestos con los que poder hacer

"J. SCHACHT, Zakât, p. 1272.

"AGS, Expte. Ha., leg. 4.

"M.A. LADERO QUESADA, El duro fisco, p. 328. En Eguilaz encontramos por asequi aderecho que se pagaba en Murcia de todo ganado menor en llegando á cuarenta cabe2asw.

"AGS, Epte. Ha., leg. 4. 
frente a los pagos a Castilla. Es posible que no siempre su valor fuera el establecido por la tradición, aunque sí en su mayoría, ya que ésta era una forma de legitimarlos.

El diezmo ( ušr) recaía sobre la producción de cereal y otras semillas. En el Quempe «del trigo e febada y paniso y hauas e todas las otras semillas que se senbravan, llevauan de diez unaw ". Desde 1492 los diezmos los recibían, junto al resto de las rentas, El Muleh y Aben Comixa quienes los dividían entre ellos, según hemos visto. A su partida en 1493 recaen sobre la Corona quien en 1545 los entregará al monasterio de la Concepción de Granada. En estas tierras, así como en todas aquéllas que entraron en el asiento del 25 de noviembre de 1491 no hubo repoblación. Los mudéjares permanecieron en su territorio con sus casas y propiedades. No obstante, poco a poco irían llegando los castellanos, primero como una oligarquía casi paralela a la mudéjar, que se instalaría en las tierras compradas a los moros. Se fueron organizando como grupo homogéneo y, más tarde, hacia 1497, comenzaron a crear las bases para un gobierno municipal ${ }^{6}$. Ello quiere decir que convivieron durante algún tiempo ambas comunidades con, entre otras cosas, regímenes fiscales diferentes. Así, en los años anteriores a la rebelión mudéjar los moros pagaban el diezmo a los frailes Jerónimos, mientras que el diezmo de los cristianos lo cobraba la Iglesia". Después de 1500 se uniformó el sistema fiscal, pagando los convertidos lo mismo que los cristianos viejos, es decir, el diezmo de todo lo producido y la alcabala de todo lo que vendían o compraban ${ }^{\prime 8}$.

Además del diezmo había otros impuestos cuyo origen estaba en la zakâ. En algunos documentos de época castellana el cequi, que deriva del término anterior, se aplicó a diversos conceptos. Así, por ejemplo, gravaba las fortunas de los granadinos con el $10 \%^{79}$. También encontramos que era un derecho de

"AGS, Cámara-Pueblos, leg. 8, fol. 276.

7 M.A. LADERo QUeSADA, Castilla y la conquista del reino de Granada, Valladolid, 1967, p.94

" «... porque los christianos que labrauan en las tierras del dicho Quenpe pagavan el diezmo a la yglesia e los moros pagavan el diesmo a los dichos frayles...n, AGS, CámaraPueblos, leg. 8, fol. 276.

73 «... que sean libres y francos y esentos desde el dia que se han convertido 0 convirtieren en adelante, para syenpre jamas de todos los derechos moriscos que nos eran obligados a dar e pagar... en tanto que las tales personas que asy se conviertieren ayan de dar e pagar desde el dicho dia que se convertieren en adelante para syempre jamas el diezmo e primiçia de todas sus labranças e crianças e de todos sus frutos e ganados e otras qualesquier cosas... e asy mismo el alcavala de todas las cosas que vendieren e conpraren en qualquier maneraw, AGS, PR, leg. 11, fol. 98.

79 «... en todos los tiempos pasados que la dicha cibdad de Granada fue de los reyes moros, el rey della acostunbrava llevar en cada un año un derecho que se llamaba el zequi, el qual se le pagaba haziendo en cada un año cierto repartimiento por los moros de la dicha 
entrada que recaía sobre las mercancías ". Este recibía el nombre de magran o magraner y consistía en el $10 \%$ que debían pagar todas las mercancías, más el 2,5\% por derecho de tránsito. Asimismo hallamos que zakî en Ibn al-Jaṭ̂b "1 significa trigo, probablemente por extensión del significado de diezmo del trigo. I. Alvárez Cienfuegos dice que se ha transferido a la documentación castellana los términos zequi o azaque como un derecho que afectaba al ganado ".

La ganadería estaba gravada con muchos impuestos, algunos de los cuales, además, presentaban valores muy distintos según sea la zona del reino de Granada a la que nos refiramos. En primer lugar, hay un "derecho de la cuenta del ganado». Este se contaba al inicio de la primavera de cada año y tributaba en el Obispado de Málaga por cada res menor entre 3 y 6 maravedís, mientras que por cada cabeza de ganado mayor entre 30 y 33 maravedis ${ }^{83}$. En el caso del Quempe el vacuno pagaba 30 maravedís, mientras que el ovino y caprino tres blancas por cabeza ${ }^{81}$. En la Relación de los derechos moriscos del Quempe de Eguilaz se menciona un derecho conocido como Ydanitaganam, del que el autor dice que obecede a las palabras árabes cidda matâ'a ganam que significa "cuenta de ganado", cuyo valor era, para el ganado menudo, de 4,5 maravedíes por cabeza ${ }^{\text {"s }}$. Pagaban, además, a los que contaban el ganado la leche de cada hato era costumbre darles un cordero para comer ${ }^{\text {Rt }}$. Esto se hacía, generalmente cuando el contador entregaba el alvalá de la cuenta que también costaba nueve maravedís ${ }^{8}$. Eguilaz menciona para el Quempe otro impuesto llamado trafi que consistía en el pago de cuatro maravedíes por cada diez cabezas para el recaudador ${ }^{*}$.

La manfa, del árabe manfáa, gravaba la reproducción del ganado con 15

cibdad, por respeto de sus bienes de moneda, de cada uno el diezmo de la moneda que trayan, segun la cantidad que se presumia que tenia, el qual diezmo diz que por su ley eran obligados a pagar a los dichos reyes moros, como el diezmo de pan e panizo e otras cosas que cogian de sus heredades...", 24 de marzo de 1493, AMG, Reales Cédulas y Provisiones, Libro I, fol. 63 en I. Álvarez Cienfuegos, la bacienda, p. 118.

* Reinhart DOZY, Supplément aux dictionnaires arabes, París-Leyden, 1967 (3* ed.).

"R. DOZY, Suppléments, s.v. zakî.

*I. Álvarez Cienfuegos, La bacienda p. 104.

"Rentas mudéjares del Obispado de Málaga, AGS, Expte. Ha, leg. 12, fol. 30, en M.A. LADERO QUESADA, El duro fisco, pp. 327 y 328; AGS, Cámara-Pueblos, leg. 8, fol. 276.

84 AGS, Cámara-Pueblos, leg. 8, fol. 276.

as L. EgUILAR YANGUAS, Glosario, s.v. Ydanitaganam.

* Idem, Glosario, s.v. bate.

' J.R. RAMOS IsABeta Política ganadera, pp. 16 y 17.

* L. Eguilar Yanguas, Glosario, s.v. trafi. 
dineros por cada 100 reses menores y 50 por cada 100 mayores ". El ganado transhumante pagaba además del magran, del árabe magram, general a tráfico de mercancias ", que suponía el $10 \%$ de su valor, otro llamado adel paso del ganadow por el que cada cabeza debían entregar 3 maravedís". Todavía en algunos lugares se tributaba el talbix que recaía sobre los ganados que permanecían algún tiempo herbajando en un término foráneo. Es decir, aunque en principio, según un hadit del Profeta el agua, la hierba y el fuego eran bienes comunes, la doctrina malikí establecía que se utilizasen las tierras a las que el ganado pudiese ir y volver en un día ${ }^{92}$. Cuando se sobrepasaba esta distancia se aplicaba un impuesto a los ganados foráneos que iban a herbajar a un término más alejado. Se pagaba por este concepto una cabeza por manada o bien una cabeza por cada pastor más una por hato ${ }^{93}$. Tenemos constancia de que se saldaba en Dalías, Valle de Lecrín, Andarax ${ }^{94}$ y Motril. En el Quempe, el criado del Muleh, Fernando de Mencoça, que antes de su conversión se llamaba Ahmet Aben Aguina, dice que el aganado que entrama a ervajan pagaba, no siendo del término, cada semana tres maravedís por cada tres reses vacunas y la misma cantidad por cada diez de ganado menor".

Las yuntas pagaban el «derecho de los pares» que tenía valores muy distintos y se tributaba de forma diferente en cada una de las regiones fiscales malagueñas a las que antes aludíamos y de las que disponemos de la relación más completa ${ }^{*}$. Por ellas sabemos que se solía satisfacer en especie y rara vez en metálico, distinguiéndose, incluso entre yuntas menores y mayores. Así, en ciertos lugares de Velez-Málaga cada una pagaba una arroba de higos y un cadahe de cebada; mientras que en Nerja se satisfacía con un cadahe de cebada y dos dineros ${ }^{9}$. En el Quempe al ser preguntado un testigo por si los ganados de arada pagaban lo mismo que el resto dijo que no ${ }^{\circ}$. En la Alpujarra almeriense

*9 Manuel ACIen Almansa, Ronda y su Serrania en tiempos de los Reyes Católicos, Málaga, 1979, p. 119.

*0 «Derecho de las mercadurias que entraren e salieren por mar e por tierraw, $\Lambda G S$, EMR, leg. 58.

91 M.A. LADero QueSADA, El duro fisco, p. 327.

92 Y. LINANT DE BELLEFONDS, Un problème de sociologie juridique, les terres comunes on pays d'Islam, «Studia Islámicaw, X (1959), pp. 111-136, espec. p. 125.

93 Angel GALÁN SÁNCHEZ, Acerca del régimen tributario nazari: el impuesto del salbix», "Actas del II Coloquio de Historia Medieval Andaluza», Sevilla, 1982, pp. 379 392.

94 AGS, Expte. Ha., leg. 4.

99 AGS, Cámara-Pueblos, leg. 8, fol. 276.

* M.A. LADERo QueSADA, El duro fisco, pp. 329-330.

${ }^{77}$ M.A. LADERO QUESADA, El duro fisco, p. 329.

98 AGS, Cámara-Pueblos, leg. 8, fol. 276. 
el derecho de los pares se llamaba "pares del çayfi y del alharif», es decir del verano y del otoño, coincidiendo con las dos cosechas anuales que se recogían en ambas estaciones $*$.

Los vecinos del Quempe señalan un derecho que debían pagar aquéllos que no lo eran por el uso del monte ya fuera para caza, carbón, o ganado, como hemos visto. Se trataba nuevamente del diezmo. Así, los que entraban a cazar debían entregar de cada diez conejos uno y los que hacían carbón tenían que dar una carga de cada diez ${ }^{100}$.

El otro derecho mencionado esta vez en relación con la actividad agrícola es la kalmaguana». Así, en las rentas del Obispado de Málaga grava en un 2,5\% el valor de los bienes raíces de los granadinos "'1. En concreto en el Quempe se especifica que recae sobre la tierra de regadío ${ }^{102}$ y que grava con 9 maravedíes cada marjal sembarado y con 4,5 el que estaba en barbecho ${ }^{103}$. Pensamos que afectaba a los bienes inmuebles en general, no sólo a los terrenos de regadío. En las rentas mudéjares de la Alpujarra se habla de «la almaguana de las tierras y los árboles" ${ }^{104}$. En en la tâ'a de Berja se nombra, incluso, una almaguana de las vacas, que probablemente se debe a una confusión con alguno de los impuestos ganaderos, tal vez con el almagran que Eguilaz identifica con la almaguana ${ }^{105}$. Las tierras de regadío en la Alpujarra estaban gravadas con un impuesto específico llamado derecho de los marjales, del que desconocemos su valor. Probablemente se tributara por lo recogido las dos veces al año en que se cosechaba, que eran el verano y el otoño, a ello corresponde la expresión "derecho de los marjales del çayfi y Alharif» aplicada en la țâa de Marchena ${ }^{106}$.

Evidentemente había más impuestos. Así, por ejemplo, el alacer gravaba en un $2,5 \%$ la producción de los frutos de los árboles y viñas. Aunque parece

99 AGS, EMR, leg. 50.

ion AGS, Cámara-Pueblos, leg. 8, fol. 276.

${ }^{101}$ M.A. LADERO QUeSADA, El duro fisco, p. 327: "Almaguana. El derecho del almaguana es un derecho que pagan los dichos moros, de quarenta maravedís uno de todo lo que valen sus casas e viñas e huertas e tierras e olivos e almendros e morales e todo otro qualquier heredamiento que tengan».

${ }^{102}$ AGS, Cámara-Pueblos, leg. 8, fol. 276: «Yten que cobravan de las tierras de riego de la Malaha, solamente de cada marja de riego no sabe quanto de vn derecho que se dize almaguanaw.

${ }^{101}$ L. Eguilaz Yanguas, Glosario, s.v. Almaguana. Lo mismo que almagran. *Almaguana, que quiere decir pecho de regar de cada marxal que estaba sembrado nueve maravedis y del que estaba fecho en barbecho cuatro y medion. Rel. de los derechos Moriscos del Quempe.

${ }^{104}$ AGS, Expte. Ha., leg. 4.

193 L. EgUILAZ YANGUAS, Glosario, s.v. almagana.

${ }^{100}$ AGS, EMR, leg. 50. 
que se aplicaba también a los olivos en algún momento después de la conquista éste se sustituye por el diezmo del aceite ${ }^{10 \prime}$. Así, pues en época mudéjar se cobraba el alacer de los frutales y de las viñas, pero no el de los olivos. En ed Quempe el de las viñas suponía 30 maravedís por marjal ${ }^{\text {lue }}$.

Sería necesario el estudio del régimen tributario nazarí en otras regiones, con objeto de sistematizar la fiscalidad de esta época, ya que como hemos podido observar en estas páginas, algunos impuestos con distintos nombres gravan, en realidad, el mismo concepto. Asimismo es fundamental establecer su relación con la de etapas precedentes. De todas formas, en este trabajo sólo pretendíamos estudiar un caso concreto, el del Quempe, al tiempo que, a través de él, nos hemos atrevido a trazar una panorámica general de este aspecto en ed reino de Granada.

${ }^{107}$ Carmen Trillo SAN JosÉ, La Alpujarra al final de la Edad Media, Tesis Doctoral inédita, Granada, 1991, tomo II, p. 666.

${ }^{108}$ L. Eguilaz YANGUAS, Glosario, s.v. alacer. 


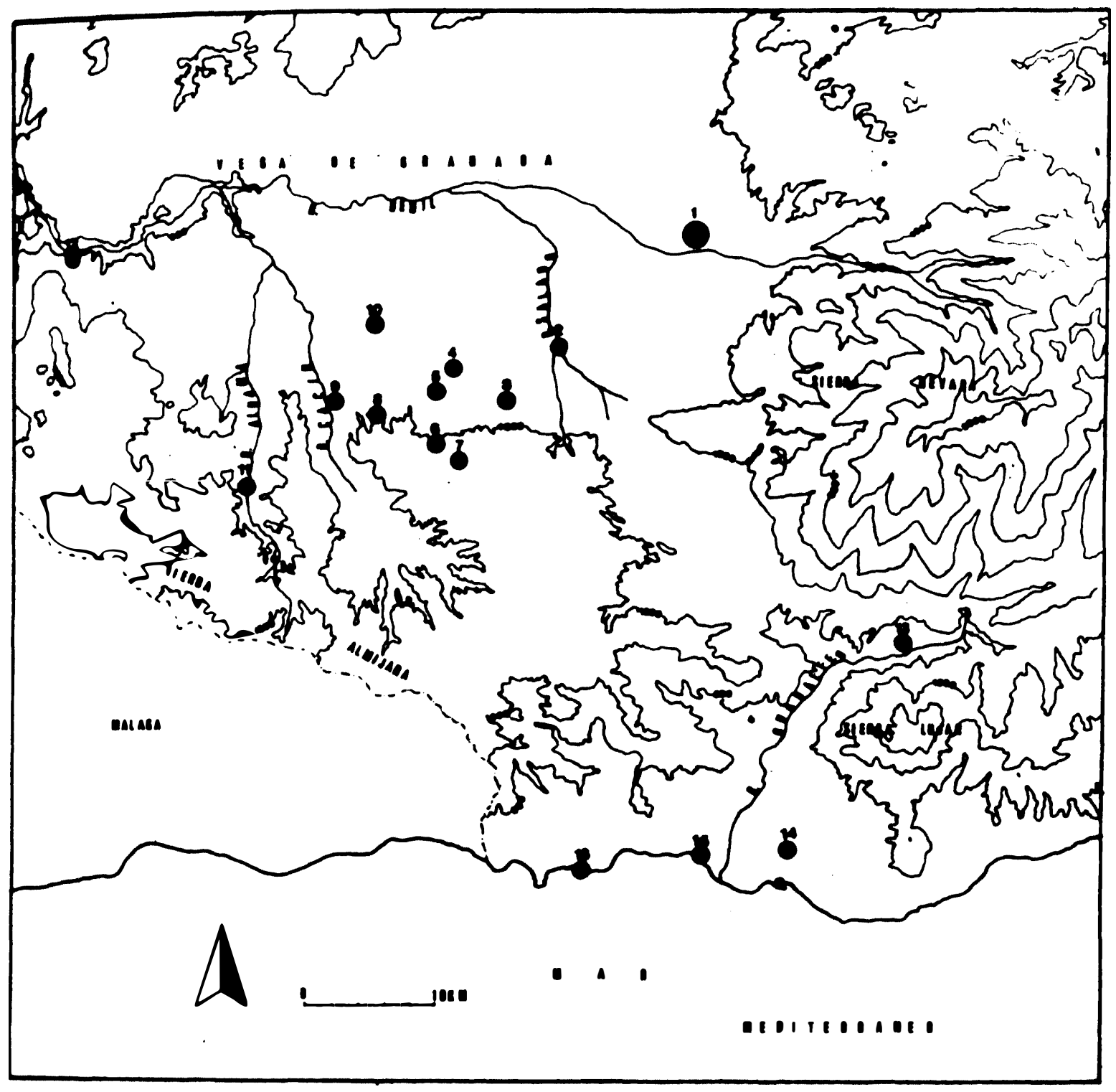

Mapa de localización de El Quempe.

1.- Granada.

2.- La Malá.

3.- Escúzar.

4.- Acula.

5.- Ventas de Huelma.

6.- La Pera.

7.- Agrón.

8.- Ochichar.
9.- Cacín.

10.- Castillo de Tajarja.

11.- Alhama de Granada.

12.- Loja.

13.- Orgiva.

14.- Motril.

15.- Salobreña.

16.- Almuñécar. 


\section{APÉNDICE DOCUMENTAL}

1495, agosto, 23. Burgos.

\section{Los Reyes Católicos conceden al monasterio de la Concepción de San Jerónimo de Granada varias rentas, entre las que se encuentran las del Quempe.}

B.- Archivo Real de la Chancillería de Granada, cab. 513, leg. 2566, pieza 38.

Nos, el rey e la reina, facemos saber a vos, los nuestros contadores maiores, que nos acatando quanto somos obligados al serbicio de Dios nuestro señor, por los muchos e continuos beneficios que de su piadosa mano avemos rescevido e cada dia rescevimos, expecialmente en la conquista del reino de Granada en que por su soberana bondad nos quiso dar complida vitoria, procuramos e fecimos que fuesen elexidas e instituidas yglesias e monesterios, cathedrales e otras yglesias en la dicha ciudad e reino de Granada. E entre ellos acordamos que fuese ynstituido cerca de la dicha ciudad de Granada y en ella çiertos monesterios, uno de los quales fuese de frailes de la orden e obidiençia e obserbancia de ${ }^{1109}$ señor San Gerónimo e el dicho menesterio se nombrase de la adbocación de la Concebción de nuestra señora Santa María, e para substentazión de dicho menesterio e del prior e // frailes e personas dél, porque ellos tengan cargo de rogar a Dios nuestro señor por nuestras vidas e estado e del príncipe don Juan e princesa de Portugal e ynfantas nuestros mui carose mui amados fixos e por las ánimas de los reies de gloriosa memoria nuestros proxenitores, e por las nuestras y porque tengan y estén proveidos de los que han menester para los edeficios e reparos e proheimentos ${ }^{111}$ del dicho monesterio e de las cosas que al culto divino son necesarias, acordamos de les dar e donar e por la presente les damos e donamos al dicho monesterio en cada un año doscientos y tres mil y quinientos maravedís de renta e más trescientos carneros e seiscientas fanegas de trigo e quatrocientas fanegas de cebada e docientas fenegas de sal e renta, todo en cada un año para siempre jamás e más dos molinos, uno de pan moler, e otro de aceite e un batán. Las quales dichas doscientas e tres mil e quinientos maravedís de renta en dineros es nuestra merced que sean situados al dicho monestero en esta guisa: los sesenta mil maravedís dellos en las tiendas que nos ovimos e conpramos de las reinas moras que fueron de la dicha ciudad de Granada, segund le son e fueron

1019) Sic.

111) Sic. 
señaladas por Fernando de Zafra, nuestro secretario, las quales de más de las tiendas que fasta aquí han entrado e entran en el arrendamiento de las rentas de la dicha ciudad de Granada e las tierras e rentas del Quempe con todas sus entradas e salidas e vsos e pertenencias que nos ovimos e compramos al Bulcaçin el Muley y de las quales fecimos merzed, así como los reies e las reinas moras de // Granada los tenían e poseían e a nos pertenecían, las quales se tasan en quinze mil maravedís de renta cada año en el honor "' de Gunien, que es en la dicha cibdad, cinco mil maravedís en la huerta que llaman Xarifa, cinco mil maravedís e en los prados e paasos ${ }^{112}$ de la Sierra Solera con sus entradas e postrueros e pertenencias, vsos e costumbres, segund fasta aquí se han arrendado e cogido segund que los tenían los reies e reinas moros a nos fueron treinta mil maravedís con tanto que la mitad de los dichos prados han de ser e es nuestra merced que sea para siempre jamás de don Iñigo Lopez de Mendoza, conde de Tendilla, nuestro capitán e alcaide de la dicha çibdad de Granada e que por la dicha su mitad de los dichos prados haia de dar e dé el dicho conde al dicho monesterio quinze mil maravedís de renta perpetua de juro de heredad situados en cada un año para siempre jamás e dando los han de dar los dicho ${ }^{113}$ prados para el dicho monesterio e para el conde e sus herederos proindivisos para lo haber e gozar por mitad, para siempre jamás, e assí que son los dichos maravedís de la dicha situazión çiento e quinze mil maravedís de renta en cada un año los otros ochenta e ocho mil e quinientos maravedís restantes a conplimiento de las dichas dosçientas e tres mil e quinientos maravedís es nuestra merced que sean situados al dicho monesterio e prior e frailes de él en qualesquier nuestras rentas de la dicha cibdad de Granada que los dichos prior e frailes del dicho monesterio quisieren e nombraren e las seicientas fanegas de trigo e quatrocientas de cevada situadas // en las nuestras rercias del arzobispado de Granada donde ellos más las quisieren é por bien tobieren en qualesquier lugar e tercias del dicho arzovispado é los dichos trecientos carneros situados en las nuestras rentas del serbicio e montadgo del passo del ganado del Puerto de Villa de Harta salidas de los ganados de los extremos de la Sulana tomados e excoxidos de las quadrillas y rebaños que ellos más quisieren e por bien tobieren que sean buenos e bibos e puestos en pie de dar e tomar a su contentamiento e las dichas doscientas fanegas de sal situadas en las nuestras salinas de La Mala que son en el reino de Granada. E los dichos molinos e batán escrevimos al arzobispo de Granada que de forma como se den al dicho monesterio e asy se cumpla la dicha mered ${ }^{114} e$ donazión que asy fecimos al dicho menesterio e prior e frailes del porque bos mandamos que lo pongades e asentedes asy en los nuestros libros e nóminas de las mercedes de juro de heredad que bozotros "tenedes e libredes al dicho prior $\mathrm{e}$ frailes del dicho menesterio de nuestra señora de la Consebción de la dicha cibdad de Granada de la dicha horden de San Gerónimo, nuestra carta de privillexo de las

III Sic por. horno.

11. Sic.

11" Sic.

114 Sic por. merced.

11 Sic. 
dichas doscientas e tres mil e quinientos maravedises, conbiene a saber por los dichor ciento e quinze mil maravedis de ellos que le dedes nuestra carta o cartas de privillejo de ellos para que haian e tengan las dichas tiendas que nos ovimos e compamos $116 / /$ de las dichas reinas moras, segund fueron señaladas por Fernando de Zafra, nuestro secretario, e de las tierras del Quempe e del dicho horno de Gumien e de la dicha huerta de Xarifa e de la mitad de los dichos prados e por la mitad de los dichos quinze mil maravedís de renta o de juro que assí ha de dar el dicho menesterio el dicho conde de Tendilla e los ochenta e ocho mil e quinientos maravedís restantes ge los dedes situados en qualesquier nuestras rentas que ellos quisieren e nombraren en la dicha ciudad de Granada e su arzovizpado "e las dichas secientas fanegas de trigo e quatrocientas de zevada e trecientos carneros e doscientas fanegas de sal de renta en cada un año e los dichos dos molinos e un batán que les sean dados por juro de heredad para siempre jamás situados e puestos por salvados señaladamente en los dichos bienes e rentas e tercias e passo de ganado e salinas suso nombradas e de la mitad de los dichos prados dat "1" previllexo al dicho conde de Tendilla por juro de heredad para siempre jamás para que los tengan proyndibisos con el dicho monesterio dando los dichos quinze mil maravedís de renta en cada un año de juro de heredad como ellos más quisieren e como dicho es para que le sea recudido con todo lo susodicho en este presente año de la fecha de este nuestro albalá desde primer dia de henero e dende en adelante en cada un año por juro de heredad para siempre jamas solamente por virtud de traslado de la dicha carta de privillejo que ansy le diéredes e libraredes e del treslado signado de escriuano público sin ser sobre escrito ny librado de vosotros nin de alguno de vos en // ningund daño e como quier que segund derecho e leies de nuestros reinos las dichas rentas que asy damos e donamos al dicho monesterio se han de pedir ante nos e ante nuestros juezes e justicias e non ante otros algunos e qualesquier dubda que naciese sobre la dicha donazión e privillejo dellas se ha de declarar por nos e por nuestros subcesores e non por otros algunos, pero por maior declarazión es nuestra merced e mandamos que agora de aquí adelante en qualquier tienpo e en qualequier manera sobre esta merced e donazión que asy facemos al dicho menesterio e sobre esta dicha nuestra albalá e sobre la dicha nuestra carta de privillejo que por virtud della le diéredes, nasciere o oviere alguna duda que sea o fuere nescesaria declarar o ynterpretar la tal declarazión o ynterpretazión, fagamos nos o los dichos nuestros subcesores que después en estos nuestros reinos subcedieren e que a nos e a ellos e non a otra persona alguna ocurrane ayan recurso sobre ello e los dichos prior e frailes que agora son e fueren del dicho monesterio.

E otrosy, que si sobre la dicha recaudanza de dichos maravedises e pan e carneros e sal o de qualquier parte dellos que los nuestros arrendadores de las dichas nuestras rentas ovieren de dar e pagar, si obieren de facear qualquier execuziones $e$ otro remedio juredico, en esto se fagan e cumpla por nuestra justicia seglar e non por ningund juez e clérigo en manera alguna e que los dichos prior e frailes de dicho

$$
\begin{aligned}
& 116 \text { Sic. } \\
& 117 \text { Sic. } \\
& 118 \text { Sic. }
\end{aligned}
$$


monesterio lo guarden y cumplan asy so pena que por el mismo caso lo contrario faciendo haian perdido e pierdan esta dicha merzed // e donazión que así les facemos sin otro sentencia nin declarazión alguna queden e se consuman en los nuestros libros para nos e para los reies nuestros subcesores por quanto es conforme a le ${ }^{1119}$ ley del quaderno que sobre lo semejante fabla e vos le descontedes diezmo nin chanzilleria de tres nin de quatro años ca por la presente les facemos merzed e limosna dello, las quales dichas nuestras cartas de privillejos que les assí diéredes e libraredes, mandamos al nuestro chanziller e notarios e oficiales que están a la tabla de los nuestros sellos que libren e passen e sellen.

Dada en la cibdad de Burgos, a veinte y tres dias del mes de julio, año del nacimiento de nuestro salvador Jesuchristo de mil e quinientos ${ }^{121}$ e noventa y cinco años. Yo, el rey. Yo, la reina. Yo, Fernando de Zafra, secretario del rey e de la reina, nuestros señores la fice escribir por su mandado.

\section{RÉSUMÉ}

La fiscalité de l'époque mudéjar, qui est le reflet, en grande partie, de celle de l'époque «nazarí» était très complexe et hétérogène et présentait de grandes différences entre les différents recoins du royaume de Grenade où il était appliqué.

Dans ce travail nous analysons, d'une manière générale, le système tributaire vers la fin du $\mathrm{XV}^{\text {tme }}$ siècle, tout en étant conscients que, déjà à ce moment là, à des dates immédiatement postérieures à la conquête, on y avait introduit d'importantes modifications. Ce sera l'analyse d'un exemple concret, celui de Quempe, qui nous permettra d'observer de près cette diversité. Il s'agit d'un ancien district, dont l'existence remonte, au moins, au XI ${ }^{\mathrm{rtm}}$ siècle, situé entre la Vega et la Vallée de Lecrin. L'étude de son régime fiscal nous permettra de connaître aussi sa richesse économique qui était basée principalement sur l'élevage et sur l'exploitation des salines. La cession de ce territoire, d'abord à Muley Hacén et à Aben Comixa et, plus tard, après la mort de ce dernier, au monastère de San Jerónimo de Grenade, est une claire démonstration de la politique de la Couronne castillane dans le règne de Grenade.

\section{SUMMARY}

The tax system during the Mudejar period which is, mostly, the reflection of the nazari's, was nevertheless more complex and heterogeneous and presented important divergences according to the different nooks of the realm of Granada where it was applied.

119 Sic.

120 Sic por: quatrocientos. 
In this study, we analyze, from a general point of view, the tributary system towards the end of the $X^{\prime h}$ century, but we are conscious of the fact that, even at that moment, immediately after the conquest, important modifications had already been introduced. It is through the analysis of a concrete example, that of Quempe, that we will be able to observe narrowly this diversity. Quempe is an old district, whose birth dates, at least, from the XI' century, located between Vega and the valley of Lecrin. The study of its fiscal regime will enable us to determine better the economic wealth, mainly based on breeding and saltworks exploitations. The fact of transferring this territory first to Muley Hacen and Aben Comixa and later, after the death of the latter, to the Granada San Jeronimo monastery, demonstrated clearly the policy of the Castilian crown in the reign of Granada. 